\title{
Front Matter: Volume 10279
}

, "Front Matter: Volume 10279," Proc. SPIE 10279, Digital Signal Processing Technology: A Critical Review, 1027901 (25 April 1995); doi:

$10.1117 / 12.2284883$

GPIE Event: SPIE's 1995 Symposium on OE/Aerospace Sensing and Dual Use Photonics, 1995, Orlando, FL, United States 


\section{Contents}

vii Conference Committee

ix Preface

DIGITAL SIGNAL PROCESSING DEVICES AND INDUSTRIAL APPLICATIONS

$3 \quad$ Integration options for signal processing systems

P. N. Ehlig, Texas Instruments Inc.

23 Adaptive active noise control systems: algorithms and digital signal processing (DSP) implementations

S. M. Kuo, Northern Illinois Univ.

50 Monitoring the health of mechanical systems with smart materials: signal processing issues

L. P. Heck, SRI International

$74 \quad$ Trends in spectral analysis: higher order and cyclic statistics G. B. Giannakis, Univ. of Virginia

DIGITAL SIGNAL PROCESSING APPLICATIONS TO SPEECH, AUDIO, AND IMAGE PROCESSING

101 Automated speech understanding: the next generation

J. Picone, W. J. Ebel, Mississippi State Univ.; N. Deshmukh, Boston Univ.

115 Speech coding for mobile and multimedia applications

A. S. Spanias, Arizona State Univ.

145 Digital audio compression algorithms and implementations J. Rowlands, Texas Instruments Inc.

170 Wavelets: a passing wave or a truly useful tool?

A. H. Tewfik, Univ. of Minnesota

198 Digital restoration of images: recent advances and future trends

A. K. Katsaggelos, Northwestern Univ.; M. R. Banham, Motorola

PARALLEL PROCESSING AND ADAPTIVE DIGITAL SIGNAL PROCESSING APPLICATIONS

231 Performance measurements of complex signal and image processing

algorithms piger multiple signal processorsystems

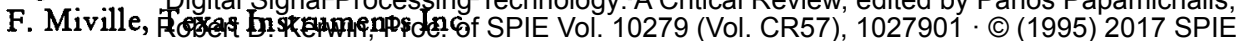

CCC code: $0277-786 \mathrm{X} / 17 / \$ 18 \cdot$ doi: $10.1117 / 12.2284883$

$\mathrm{V}$

Proc. of SPIE Vol. 10279 1027901-1

Downloaded From: https://www.spiedigitallibrary.org/conference-proceedings-of-spie on 26 Apr 2023 
250 Execution of parallel algorithms on a heterogeneous multicomputer B. S. Isenstein, J. Greene, Mercury Computer Systems, Inc.

277 Parallel processing architectures for image processing systems M. D. Vahey, R. Cody, Hughes Aircraft Co.

291 CORDIC-based digital signal processing (DSP) element for adaptive signal processing

G. D. Bolstad, K. B. Neeld, Hughes Aircraft Co.

314 Digital systems for neural networks

P. Ienne, EPFL Microcomputing Lab. (Switzerland); G. Kuhn, Siemens Corporate Research Learning Systems 


\title{
Conference Committee
}

\author{
Conference Chairs
}

Panos Papamichalis, Texas Instruments Inc.

Robert Kerwin, Hughes Aircraft Company

\section{Session Chairs}

1 Digital Signal Processing Devices and Industrial Applications

Panos Papamichalis, Texas Instruments Inc.

2 Digital Signal Processing Applications to Speech, Audio, and Image Processing

Joseph Picone, Mississippi State University

3 Parallel Processing and Adaptive Digital

Signal Processing Applications

Robert Kerwin, Hughes Aircraft Company 
Proc. of SPIE Vol. 10279 1027901-4 Downloaded From: https://www.spiedigitallibrary.org/conference-proceedings-of-spie on 26 Apr 2023
Terms of Use: https://www.spiedigitallibrary.org/terms-of-use 


\section{Preface}

Digital signal processing (DSP) has made significant inroads into practically every commercial and military signal processing application. It has even started penetrating consumer applications, such as digital audio and video. The reasons are the ability to develop highly sophisticated algorithms, and the availability of fast and inexpensive devices to implement these algorithms.

This Critical Reviews volume addresses both the hardware and the algorithmic aspects of DSP. From the hardware standpoint, programmable and dedicated devices are considered, with input/output, memory, and architectural features covering several areas of applications. The main focus, though, is on algorithmic applications.

The algorithmic developments, presented in three sessions, address industrial applications, speech, audio, image processing, parallel processing, and adaptive DSP applications.

We would like to thank the authors for their excellent papers, and the SPIE staff for their assistance with the organization of this meeting and the preparation of the proceedings.

Panos Papamichalis Robert Kerwin 